\title{
Antepartum transabdominal amnioinfusion in oligohydramnios - a comparative study
}

\author{
Nihida Akhter ${ }^{1}$, Shahnaz Taing², Irfan Nazir Mir ${ }^{3}$, Nadeem Ahmad 4 , \\ Tufail A. Sheikh5 ${ }^{5}$ Mir Mujtaba Ahmad ${ }^{6 *}$
}

\begin{abstract}
${ }^{1}$ Registrar, ${ }^{2}$ Professor \& Head, Department of OB\&G, ${ }^{3} \mathrm{PG}$ Scholar, ${ }^{6}$ Registrar, Department of Surgery, ${ }^{4}$ Registrar, Department of Medicine, GMC, Srinagar, India

${ }^{5} \mathrm{PG}$ scholar, Department of Anaesthesiology, SKIMS, India
\end{abstract}

Received: 21 June 2015

Accepted: 10 July 2015

\section{*Correspondence:}

Dr. Mir Mujtaba Ahmad,

E-mail: drmirmujtaba1@gmail.com

Copyright: (c) the author(s), publisher and licensee Medip Academy. This is an open-access article distributed under the terms of the Creative Commons Attribution Non-Commercial License, which permits unrestricted non-commercial use, distribution, and reproduction in any medium, provided the original work is properly cited.

\begin{abstract}
Background: The purpose of this study was to evaluate the role of antepartum transabdominal amnioinfusion in oligohydramnios with the view to improving pregnancy outcome in oligohydramnios, a serious complication of pregnancy that is associated with a poor perinatal outcome and complicates $1-5 \%$ of pregnancies.

Methods: The study comprised of a prospective analysis of 130 pregnant women with oligohydramnios, divided into two groups, the study and control group of 65 patients each and were similar with regard to age, gravidity, parity, gestational age. TAA was performed on all patients in the study group and the results were compared and analyzed.

Results: Mean gestational age at first treatment was 29.98 weeks in study group. Mean pre-procedure amniotic fluid index was 4.01 and post-procedure was 12.49. A total of 106 infusions were done on 65 patients (mean1.63). Mean latency period in study group was 49.53 and in controls 26.49. There was significant decrease in fetal distress in patients in study group. $30 \%$ of patients needed caesarean section in study group compared to $60 \%$ in controls. Number of preterm deliveries was 18 and 45 respectively in study and control groups. $61 \%$ of newborns in the study group weighed more than $2.5 \mathrm{~kg}$ compared to only $24 \%$ in control group. Neonatal ICU admissions and newborn deaths were lesser in study group.

Conclusions: Transabdominal amnioinfusion is an extremely useful procedure to reduce complications arising from oligohyramnios. It significantly increases the latency period, decreases the occurrence of fetal distress preterm deliveries, need for caesarean or instrumental deliveries, improves birth weight of the newborns and significantly reduces the neonatal morbidity and mortality.
\end{abstract}

Keywords: Transabdominal amnioinfusion, Amniotic fluid index, Oligohydramnios

\section{INTRODUCTION}

Oligohydramnios is defined as a single reading of the amniotic fluid index (AFI) below $5 \mathrm{~cm}$ or 3 readings below $8 \mathrm{~cm}^{1}$ Phelan first introduced AFI in 1987 which is an objective and reproducible method of estimating amniotic fluid. Although Oligohydramnios affects only $4-5.5 \%$ of all pregnancies, ${ }^{2}$ it is a serious complication of pregnancy that is associated with a poor perinatal outcome. Oligohydramnios is an important problem due to its severe complications which include antepartum and intrapartum fetal death, cord prolapse or compression, compression related limb deformities, and pulmonary hypoplasia. Clinically the most serious consequence of oligohydramnios is pulmonary hypoplasia, which carries a mortality rate of up to $80 \%{ }^{3}$ Another serious consequence 
is abnormal neurological outcome. A normal amniotic fluid volume is critical for normal fetal growth and development. Oligohydramnios is associated with increased perinatal morbidity and mortality at any gestational age, but the risks are relatively high when it is detected during second trimester. Prolonged oligohydramnios in the 2nd and 3rd trimester leads to deformation sequence in $10-15 \%$ of cases, characterised by cranial, facial and skeletal abnormalities. An AFI of $<5 \mathrm{~cm}$ requires prompt additional antenatal testing rather than immediate induction in low risk term pregnancies. Severe oligohydramnios identified in second trimester is an indication that perinatal outcome will be poor. Oligohydramnios poses not only a diagnostic challenge but also a dilemma of management for the obstetricians. The general outcome is usually poor. Near term, it has been associated with complications of labour and delivery. There is increased incidence of meconium stained liquor, abnormal FHR tracing, prolonged labour, increased rate of induction, increased incidence of operative intervention due to malpresentations, fetal distress and its associated morbidity and mortality, low Apgar score, low birth weight, admission to NICU, birth asphyxia.

Antepartum amnioinfusion involves artificially increasing the amniotic fluid volume by injecting normal saline or Ringer lactate solutions into the amniotic cavity transabdominally. The objective is to prolong the gestational period by augmenting the amniotic fluid volume ${ }^{4}$ which may also decrease the associated risks of oligohydramnios and increase perinatal survival. The 2006 National Institute of Clinical Excellence (NICE) guidelines currently state that oligohydramnios is not routinely treated in pregnancy. ${ }^{5}$ Conservative expectant management for the prolongation of gestation ${ }^{4}$ is therefore the commonly practiced approach.

Because of the high morbidity and mortality of second trimester oligohydramnios, termination of pregnancy is usually offered. ${ }^{6}$ The aim of this study is to assess the outcome in pregnancies complicated by oligohydramnios that were managed by amnioinfusion, and to evaluate the effect of amnioinfusion on the latency period, which refers to the time from treatment to delivery. It has been proven to be safe and effective. It can be prophylactic, diagnostic, or therapeutic.

Two techniques are used for amnioinfusion:

- Transabdominal

- Transvaginal

\section{Aims \& objective}

- Purpose of this study was to assess the role of antepartum transabdominal amnioinfusion in preterm pregnancies with oligohydramnios.

- To evaluate the effect of antepartum transabdominal amnioinfusion on amniotic fluid volume, latency period and on operative interference in pregnancies with oligohydramnios.

- To evaluate the role of transabdominal amnioinfusion in reducing complications resulting from oligohydramnios.

\section{METHODS}

A randomized controlled study was conducted in the department of obstetrics and gynaecology at Govt. Lalla Ded Hospital Srinagar from March 2012 - September 2013. The study comprised of a prospective analysis of 130 pregnant patients with oligohydramnios. All pregnant females with oligohydramnios (AFI $<5 \mathrm{cms}$ ) with maternal age between 20-34 years, gestational age of 28-34 weeks, parity from 1-4, singleton pregnancy, cephalic presentation, with intact membranes, and a reactive CTG at admission were matched for age, parity and pregnancy duration and divided into two groups, the study and the control group respectively of 65 patients each. A written informed consent was taken. Twenty-four hours after admission pregnant women were randomly assigned to study and control groups respectively. Transabdominal amnioinfusion was performed on all patients in the study group and the control group was managed expectantly. The results were compared and analyzed.

\section{RESULTS}

In this study of 130 pregnant women both groups were comparable with regard to antepartum variables i.e. maternal age, gravidity, parity, gestational age and AFI at presentation.

Mean AFI pre and post amnioinfusion in study group was $4.10 \mathrm{~cm}$ and $12.48 \mathrm{~cm}$, and that in control group was $4.11 \mathrm{~cm}$. Fetal distress as reflected from non-reactive stress test, fetal heart deceleration, thick meconium, was significantly reduced in the study group. The mean latency in the study and control was 49.5 days and 26.4 days respectively, which was significant. Spontaneous deliveries $(36.92 \%)$ were significantly higher in the study group compared to controls (16\%). In the study group lesser number of patients required operative intervention (30\%) compared to $60 \%$ using LSCS in control group.The mean Apgar score in the study group at 1 and 5 min. was 6.61 and 8.92 and that in controls 5.80 and 6.66 respectively.In our study $61 \%$ of newborns weighted $>2.5 \mathrm{~kg}$ in the study group compared to only $24 \%$ newborns weighing $>2.5 \mathrm{~kg}$ in control group. There was significant reduction of neonatal admission to NICU and neonatal deaths in the study group compared to the controls.

Table 1: Characteristics of study and control group at admission.

\begin{tabular}{|llll|}
\hline & Number of & Study group & Controls \\
\hline 1. & $\begin{array}{l}\text { Nutients } \\
\text { Pats }\end{array}$ & 65 \\
\hline 2. & Maternal Age & 26.3 & 26.5 \\
\hline
\end{tabular}




\begin{tabular}{|c|c|c|c|}
\hline & $\begin{array}{l}\text { (Mean) in } \\
\text { years }\end{array}$ & & \\
\hline 3. & Gravidity & & \\
\hline & G1 & $31(47.6 \%)$ & $30(46.1 \%)$ \\
\hline & G2 & $17(26.15)$ & $16(24.6 \%)$ \\
\hline & G3 & $13(20 \%)$ & $15(23 \%)$ \\
\hline & G3 & $4(6.15 \%)$ & $4(6.15 \%)$ \\
\hline 4. & Parity & & \\
\hline & P0 & $48(73 \%)$ & $44(67.69 \%)$ \\
\hline & $\mathrm{P} 1$ & $13(20 \%)$ & $16(24.61 \%)$ \\
\hline & p2 & $4(6.15)$ & $3(4.61 \%)$ \\
\hline & P3 & 0 & $2(3.01)$ \\
\hline 5. & $\begin{array}{l}\text { Number of } \\
\text { previous } \\
\text { abortions }\end{array}$ & & \\
\hline & 0 & $42(64.6 \%)$ & $40(61.54 \%)$ \\
\hline & 1 & $19(29.2 \%)$ & $22(33.8 \%)$ \\
\hline & 2 & $4(6.15 \%)$ & $3(4.62 \%)$ \\
\hline 6. & $\begin{array}{l}\text { Mean AFI } \\
\text { (in cms) }\end{array}$ & 4.01 & 4.11 \\
\hline
\end{tabular}

Table 2: Various studied parameters following TAA in study group.

\begin{tabular}{|c|c|c|c|}
\hline & & Studygroup & Controls \\
\hline 1. & $\begin{array}{l}\text { Mean No. of } \\
\text { TAA }\end{array}$ & 1.63 & - \\
\hline 2. & $\begin{array}{l}\text { Mean } \\
\text { AFI(in cms) } \\
\text { at admission }\end{array}$ & 4.01 & 4.11 \\
\hline 3. & $\begin{array}{l}\text { Mean } \\
\text { AFI(in cms) } \\
\text { after TAA }\end{array}$ & 12.49 & \\
\hline \multirow[t]{3}{*}{4.} & $\begin{array}{l}\text { Non-Stress } \\
\text { Test }\end{array}$ & & \\
\hline & Reactive & $60 \%$ & $30.70 \%$ \\
\hline & $\begin{array}{l}\text { Non- } \\
\text { Reactive }\end{array}$ & $40 \%$ & $69.30 \%$ \\
\hline 5. & $\begin{array}{l}\text { Late } \\
\text { decelration }\end{array}$ & $9 / 65(13.8 \%)$ & $15 / 65(2.3 \%)$ \\
\hline 6. & $\begin{array}{l}\text { Variable } \\
\text { Decelration }\end{array}$ & $5 / 65$ (7.69) & $\begin{array}{l}30 / 65 \\
(46.1 \%)\end{array}$ \\
\hline \multirow[t]{4}{*}{7.} & $\begin{array}{l}\text { Meconium } \\
\text { type }\end{array}$ & & \\
\hline & Clear & $40(61.5 \%)$ & $20(30.76 \%)$ \\
\hline & Thick & $12(18.4 \%)$ & $10(15.3 \%)$ \\
\hline & Thin & $13(20 \% 0$ & $35(53.84 \%)$ \\
\hline \multirow[t]{3}{*}{8.} & $\begin{array}{l}\text { Types of } \\
\text { Labour }\end{array}$ & & \\
\hline & Induced & $41(63 \%)$ & $54(83 \%)$ \\
\hline & Spontaneous & $24(36.9 \%)$ & $11(16.92)$ \\
\hline \multirow[t]{4}{*}{9.} & $\begin{array}{l}\text { Mode of } \\
\text { Delivery }\end{array}$ & & \\
\hline & Vaginal & $40(61.53 \%)$ & $16(24.61)$ \\
\hline & LSCS & $20(30.76 \%)$ & $39(60 \%)$ \\
\hline & Instrumental & $5(7.69 \%)$ & $10(15.38 \%)$ \\
\hline 10. & Mean & & \\
\hline
\end{tabular}

\begin{tabular}{|c|c|c|c|}
\hline & $\begin{array}{l}\text { gestation } \\
\text { age (at } \\
\text { delivery) }\end{array}$ & & \\
\hline 11. & $\begin{array}{l}\text { Latency } \\
\text { (Mean)(In } \\
\text { Days) }\end{array}$ & 49.5 & 26.4 \\
\hline 12. & $\begin{array}{l}\text { No. of } \\
\text { Preterm } \\
\text { Deliveries }\end{array}$ & $18(27.69 \%)$ & $45(69.23 \%)$ \\
\hline 13. & $\begin{array}{l}\text { Mean } \\
\text { APGAR } \\
\text { Score }\end{array}$ & & \\
\hline & At $1 \mathrm{~min}$ & 6.61 & 5.8 \\
\hline & At 5 Min & 8.92 & 6.66 \\
\hline 14. & $\begin{array}{l}\text { Birth } \\
\text { Weight }>2.5 \\
\mathrm{~kg}\end{array}$ & $61 \%$ & $24 \%$ \\
\hline 15. & $\begin{array}{l}\text { Admission } \\
\text { of newborn } \\
\text { to NICU }\end{array}$ & $14(21.5 \%)$ & $32(49.2 \%)$ \\
\hline 16. & $\begin{array}{l}\text { No. of } \\
\text { neonatal } \\
\text { deaths }\end{array}$ & $293.07 \%)$ & $12(18.46 \%)$ \\
\hline
\end{tabular}

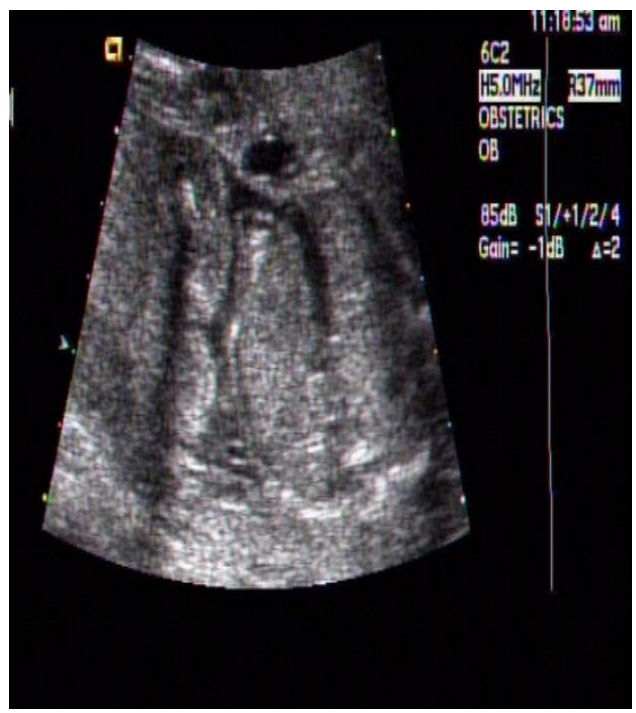

Figure 1: Before second trimester amnioinfusion.

\section{DISCUSSION}

Oligohydramnios complicates $1-5 \%$ of pregnancies. It leads to various fetal and maternal complications.

\section{Fetal complications}

Cord compression and fetal distress, fetal pulmonary hypoplasia and stillbirth, fetal growth restriction, low Apgar score, NICU admission and fetal mortality. 


\section{Maternal complications}

Prolonged labour due to inertia, Induction of labour, increased incidence of operative intervention due to malpresentations and its associated morbidity and mortality.

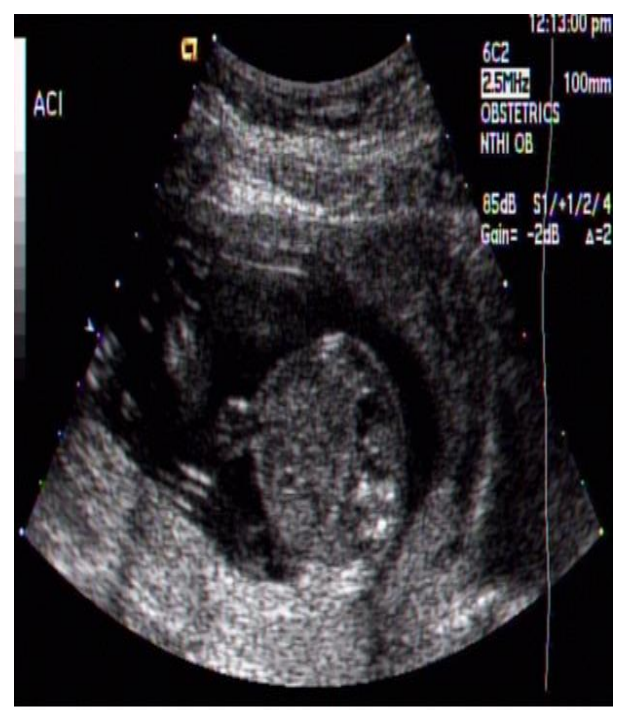

Figure 2: After second trimester amnioinfusion.

Oligohydramnios poses not only a diagnostic challenge but also a dilemma of management for the obstetrician. The general outcome is usually poor, no matter whatever, is the cause of oligohydramnios. The purpose of the present study was to determine the usefulness of antepartum transabdominal amnioinfusion in reducing the perinatal ill effects of oligohydramnios and effect of amnioinfusion on various parameters like amniotic fluid volume (AFV), latency period, need for operative intervention, reduction in associated complications, perinatal morbidity and mortality. In our study with this procedure i.e. (antepartum transabdominal amnioinfusion), we found a significant increase in (amniotic fluid index, latency period, newborn birth weight score), and a decrease in (fetal distress, need for operative intervention, and neonatal morbidity and mortality) respectively. The procedure of antepartum transabdominal amnioinfusion is easy, safe, simple, inexpensive and extremely useful procedure for uncomplicated pregnancies with oligohydramnios, with no apparent maternal or fetal risk and it potentially improves maternal and neonatal outcome. By replenishing the lost amniotic fluid it optimizes neonatal survival by reducing intrapartum fetal distress. During our study no significant adverse effect related to the procedure was noted. There was no reported maternal death during the study and follow up period. There were many cases of precious pregnancies in our study, who had a favourable outcome after transabdominal amnioinfusion. The procedure of antepartum transabdominal amnioinfusion is a promising therapeutic modality for the reduction of fetal morbidity and mortality. The procedure is effective and easy to perform with benefits clearly outweighing the risks. Optimizing the selection of patients who are good candidates for the procedure is a prerequisite.

\section{CONCLUSION}

Antepartum transabdominal amnioinfusion is an extremely useful, safe and effective procedure to reduce complications arising from oligohydramnios. It significantly increases the latency period, decreases the occurrence of fetal distress, preterm deliveries, need for caesarean or instrumental deliveries, improves birth weight of the newborns and significantly reduces the neonatal morbidity and mortality.

\section{Funding: No funding sources Conflict of interest: None declared \\ Ethical approval: The study was approved by the Institutional Ethics Committee}

\section{REFERENCES}

1. Vergani P, P Ceruti, N Strobelt, A Locatelli, G D’Oria, S Manani. Transabdominal amnioinfusion in oligohydramnios at term before induction of labour with intact membranes: a randomized clinical trial. Am J Obstet Gynaecol 1996;175:465-470.

2. Callen PW. Amniotic fluid volume: its role in fetal health and disease. In: Callen PW, ed. Ultrasonography in obstetrics and gynaecology. 4th ed. Philadelphia, PA: WB Saunder Co 2000, pp 638-659.

3. Vergani P, Ghidini A, Locatelli A. Risk factors for pulmonary hypoplasia in second-trimester premature rupture of membranes. Am J Obstet Gynaecol 1994;170:1359-64.

4. Turhan NO, Atacan N. Antepartum prophylactic transabdominal amnioinfusion in preterm pregnancies complicated by oligohydramnios. Int J GynaecolObstet 2002;76:15-21.

5. National Institute for Health and Clinical Excellence (NICE) - UK. Therapeutic amnioinfusion for oligohydramnios during pregnancy (excluding labour). Published by theNational Institute for Health and Clinical Excellence, November 2006; ISBN 184629-300-6.

6. Ogunyemi D, Thompson W. A case controlled study of serial Transabdominal amnioinfusion in the management of second Trimester oligohydramnios due to premature rupture of membranes. Eur J Obstet Gynaecol Reprod Biol 2001;102:167-72.

Cite this article as: Akhter N, Taing S, Mir IN, Ahmad N, Sheikh TA, Ahmad MM. Antepartum transabdominal amnioinfusion in oligohydramnios a comparative study. Int $\mathrm{J}$ Reprod Contracept Obstet Gynecol 2015;4:1181-4. 